\title{
CMSX- $4{ }^{\circledR}$ PLUS SINGLE CRYSTAL ALLOY DEVELOPMENT, CHARACTERIZATION AND APPLICATION DEVELOPMENT
}

\author{
Jacqueline B. Wahl ${ }^{1}$ and Ken Harris ${ }^{1}$ \\ ${ }^{1}$ Cannon-Muskegon ${ }^{\circledR}$ Corporation, 2875 Lincoln St, Muskegon, MI 49441-0506, USA
}

Keywords: CMSX-4 ${ }^{\circledR}$ Plus, Cast, Single Crystal, Alloy Development, Properties

\begin{abstract}
Ongoing demand for advanced gas turbines with lower fuel burn and commensurate reduced $\mathrm{CO}_{2}$ emissions require single crystal (SX) superalloys that can be cast into complex cooled turbine blades and vanes, including dual wall, capable of operating at higher gas and metal temperatures beyond the capability of $2^{\text {nd }}$ generation, 3\% rhenium ( $\mathrm{Re}$ )-containing SX alloys, currently used extensively in commercial and military flight engines. These castings must have an excellent balance of high temperature mechanical properties, producibility, oxidation/hot corrosion resistance, coating compatibility and phase stability.
\end{abstract}

The highest strength nickel-base SX superalloys, without ruthenium, currently in production $\left(3^{\text {rd }}\right.$ generation CMSX-10K ${ }^{\circledR}$ and CMSX-10N ${ }^{\circledR}$ alloys) contain 6-7\% Re. These highly alloyed, specialty alloys have in some applications demonstrated drawbacks including secondary reaction zone (SRZ) phase instability in the base alloy adjacent to the coatings, low temperature internal oxidation/hot corrosion attack and difficulty in production solution heat treatment. In addition, current $3^{\text {rd }}$ generation SX alloys have high density which is a disadvantage in terms of weight and inertia for rotating part applications, and high cost due to the elevated Re content.

In response, Cannon-Muskegon (CM) has developed an improved, lower Re content $3^{\text {rd }}$ generation SX superalloy, CMSX-4 ${ }^{\circledR}$ Plus, suitable to replace both current $2^{\text {nd }}$ and $3^{\text {rd }}$ generation SX alloys, with improved properties and performance and lacking the drawbacks of current $3^{\text {rd }}$ generation SX alloys. The development and characterization of CMSX-4 Plus alloy, including composition, mechanical and physical properties are detailed in this paper.

\section{Background}

There is ongoing demand for advanced gas turbines with lower fuel burn and corresponding reduced $\mathrm{CO}_{2}$ emissions. To meet these requirements, there is a need for single crystal ( $\mathrm{SX}$ ) superalloys that can be cast into very complex cooled turbine blades and vanes capable of operating at higher gas and metal temperatures beyond the capability of $2^{\text {nd }}$ generation, $3 \%$ rhenium (Re)-containing SX alloys. These include alloys such as $\mathrm{CMSX}-4^{\circledR}$, PWA 1484 and Rene' N5, which are used extensively in commercial and military flight engines. These castings must have not only excellent high temperature properties, but also good producibility in terms of castability and solution heat treatment, good oxidation/hot corrosion resistance, coating compatibility and phase stability.

Single crystal nickel (Ni) base superalloys typically contain high levels of refractory elements such as molybdenum (Mo), tungsten (W), rhenium ( $\mathrm{Re}$ ) and tantalum (Ta) in order to improve high temperature creep-rupture properties. However, high levels of these elements can result in formation of topologically closepacked (TCP) phases during high temperature stressed exposure. TCP phases are rhenium and tungsten rich with some chromium (Cr). Excessive formation of TCP phases de-alloy the material, resulting in premature crack initiation and reduced creep-rupture strength. Consequently, successful alloy development requires selecting the appropriate levels of refractory elements and $\mathrm{Cr}$ content to achieve the delicate balance of strength properties against long term phase stability.

The highest strength Ni-base SX superalloys, without ruthenium $(\mathrm{Ru})$, currently in production for flight engines contain 5-7 wt $\% \mathrm{Re}$. These include CMSX-10K ${ }^{\circledR}$ and CMSX-10N ${ }^{\circledR}$ alloys developed by Cannon-Muskegon Corporation [1,2], and René N-6 alloy developed by the General Electric Company [3]. Due to high Re content, these specialty alloys have in certain applications exhibited undesirable features. These alloys tend to develop a phase instability know as secondary reaction zone (SRZ) in the base alloy adjacent to the coatings, and when excessive, results in coating compatibility and thin-wall mechanical property issues [4]. Alloys CMSX-10K and CMSX-10N have a very low Cr content (1.5 and $2.2 \mathrm{wt} \%$, respectively), which reduces low temperature internal oxidation and hot corrosion resistance. These alloys also have high $\gamma^{\prime}$ solvus temperatures requiring very high temperature solution heat treatment, which can result in surface melting issues during production-size vacuum heat treatment. Moreover, current $3^{\text {rd }}$ generation SX alloys have high density which is a disadvantage in terms of weight and inertia for rotating part applications, and high cost due to the elevated Re content, which is a rare, limited availability element by-product of copper and/or copper/molybdenum mining and extraction.

In response, Cannon-Muskegon (CM) initiated work on development of a new SX superalloy with improved properties over CMSX-4 alloy, while addressing the undesirable aspects of current $3^{\text {rd }}$ generation SX alloys. The development goals included properties approaching the $\mathrm{CM} 3^{\text {rd }}$ generation $(6-7 \% \mathrm{Re})$ alloys, excellent castability, improved solution heat treatment capability, no SRZ phase/coating compatibility issues, improved oxidation/hot corrosion resistance and lower Re content, cost and density.

\section{Composition}

The nominal chemistry of CMSX-4 Plus alloy is shown in Table I [5]. The alloy chemistry was developed from $\mathrm{CMSX}^{\circledR}-8$ and CMSX-4 alloys [6-8]. CMSX-8 is a $1.5 \mathrm{wt} \%$ Re containing alloy 
with excellent SX castability, high temperature oxidation resistance and creep-rupture properties close to, but somewhat less than, CMSX-4 alloy.

Table I. Nominal Chemistry of CMSX-4 Plus Alloy

\begin{tabular}{|c|c|c|c|}
\hline Element & $\mathrm{Wt} \%$ & Element & $\mathrm{Wt} \%$ \\
\hline $\mathrm{Cr}$ & 3.5 & $\mathrm{Re}$ & 4.8 \\
\hline $\mathrm{Co}$ & 10 & $\mathrm{Al}$ & 5.7 \\
\hline $\mathrm{Mo}$ & 0.6 & $\mathrm{Ti}$ & 0.85 \\
\hline $\mathrm{Ta}$ & 8 & $\mathrm{Hf}$ & 0.1 \\
\hline $\mathrm{W}$ & 6 & $\mathrm{Ni}$ & Balance \\
\hline
\end{tabular}

Specifically for CMSX-4 Plus, Re content was increased compared to CMSX-4 alloy for improved creep-rupture properties, balanced against the adverse effects of SRZ phase and formation of TCP phases. Consistent with CMSX-8 alloy, Ta content was held at 8 wt.\% for good castability and to minimize the propensity for the formation of "freckle" grain SX casting defects. Cr content was adjusted to maintain phase stability with the increased Re content, but is higher than CMSX-10K/N alloys for improved low temperature oxidation and hot corrosion/sulfidation resistance. Mo was kept very low for optimum oxidation properties. This necessitated using titanium (Ti) to achieve appropriate $\gamma / \gamma^{\prime}$ mismatch and interfacial chemistry for optimum microstructure and creep-rupture properties. Ti also helps to reduce alloy density. A small hafnium (Hf) addition ensures an acceptable solution heat treatment window while aiding oxidation performance and coating adherence. The aluminum (Al), Ti and Ta contents were balanced to obtain approximately $70 \%$ volume fraction $\gamma^{\prime}$ phase ( $\left.\mathrm{Ni}_{3} \mathrm{Al}, \mathrm{Ti}, \mathrm{Ta}\right)$, and high $\mathrm{Al}$, low Mo with the Hf addition produce improved bare alloy oxidation resistance and coating adherence.

Table II. CMSX-4 Plus Developmental Chemistries (Wt \%)

\begin{tabular}{|l|l|l|l|}
\hline Element & Mod A & Mod B & Mod C \\
\hline $\mathrm{Cr}$ & 4.2 & 4 & 3.5 \\
\hline $\mathrm{Co}$ & 10 & 10 & 10 \\
\hline $\mathrm{Mo}$ & 0.6 & 0.6 & 0.6 \\
\hline $\mathrm{Ta}$ & 8 & 8 & 8 \\
\hline $\mathrm{W}$ & 5 & 6 & 6 \\
\hline $\mathrm{Re}$ & 4.0 & 4.5 & 4.8 \\
\hline $\mathrm{Al}$ & 5.8 & 5.7 & 5.7 \\
\hline $\mathrm{Ti}$ & 0.65 & 0.8 & 0.85 \\
\hline $\mathrm{Hf}$ & 0.1 & 0.1 & 0.1 \\
\hline $\mathrm{Ni}$ & Balance & Balance & Balance \\
\hline
\end{tabular}

The development work included evaluation of three chemistry modifications, Mod A, B and C (Table II) [9]. The alloy modifications were assessed in terms of solution heat treatment capability, mechanical and physical properties. It is interesting to note that based on the work of A. Giamei and others from early SX alloy development it has generally held that creep properties improve linearly with increased Re content (Figures 1-2) [10]; however, examination of $8 \%$ Ta-containing CMSX alloys CMSX8 and CMSX-4 Plus Mod A, B and C creep versus Re content show a surprising exponential relationship (Figure 3), with a significant improvement in creep properties for relatively small changes in alloy chemistry (Table III).

Based on extensive testing and characterization, CMSX-4 Plus Mod C alloy was determined to be the best all-round composition. The balance of this paper will present characterization of Mod C, henceforth described simply as CMSX -4 Plus alloy.

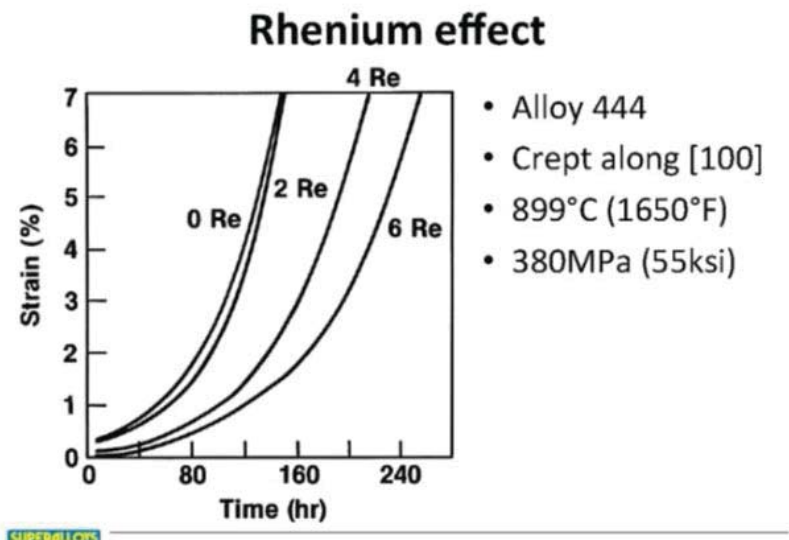

September 9-13, 2012-Seven Springs, Pennsylvania

Figure 1. "Rhenium Effect" per A. Giamei Superalloys 2012 Dedicatee Presentation

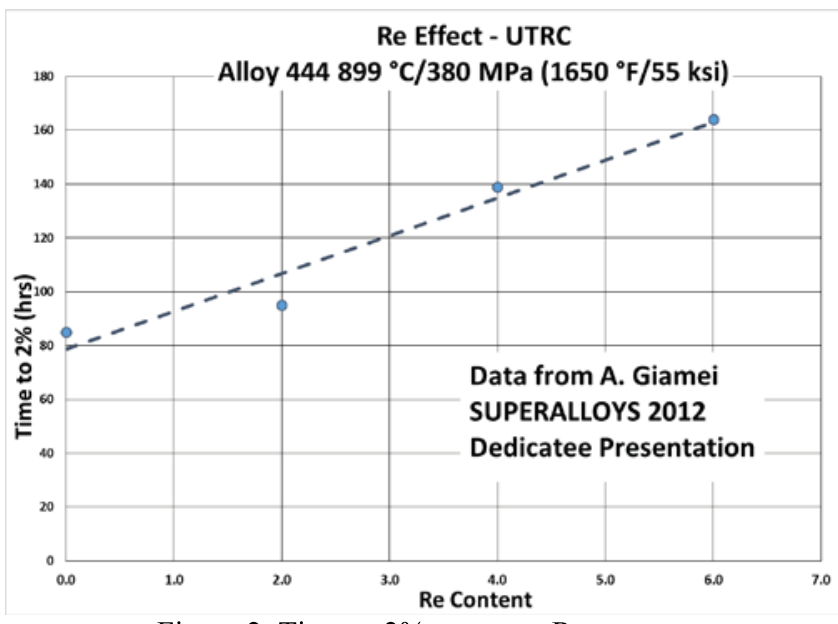

Figure 2 . Time to $2 \%$ creep vs. Re content derived from Fig. 1 "Rhenium Effect"

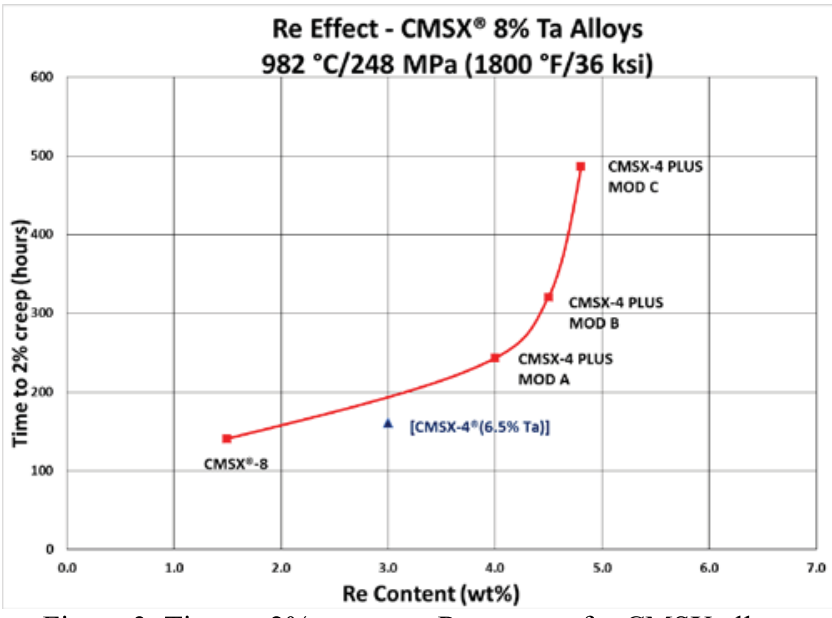

Figure 3 . Time to $2 \%$ creep vs. Re content for CMSX alloys 
Table III. Comparative Creep/Stress Rupture Properties (hours)

\begin{tabular}{|c|c|c|c|}
\hline CMSX-4 Plus Variant & Mod A & Mod B & Mod C \\
\hline $\begin{array}{c}982^{\circ} \mathrm{C} / 248 \mathrm{MPa} \\
\left(1800^{\circ} \mathrm{F} / 36 \mathrm{ksi}\right)\end{array}$ & & & \\
\hline Time to $1 \%$ creep & 209 & 280 & 433 \\
\hline Time to $\%$ creep & 243 & 320 & 486 \\
\hline Rupture Life & 398 & 493 & 732 \\
\hline $\begin{array}{c}1010^{\circ} \mathrm{C} / 248 \mathrm{MPa} \\
\left(1850^{\circ} \mathrm{F} / 36 \mathrm{ksi}\right)\end{array}$ & & & \\
\hline Time to $1 \%$ creep & 73 & 89 & 130 \\
\hline Time to $2 \%$ creep & 85 & 103 & 147 \\
\hline Rupture Life & 139 & 169 & 227 \\
\hline $\begin{array}{c}1050{ }^{\circ} \mathrm{C} / 190 \mathrm{MPa} \\
\left(1922^{\circ} \mathrm{F} / 27.6 \mathrm{ksi}\right)\end{array}$ & & & \\
\hline Time to $1 \%$ creep & 70 & 83 & 118 \\
\hline Time to $\% \%$ creep & 87 & 110 & 138 \\
\hline Rupture Life & 143 & 184 & 231 \\
\hline $\begin{array}{c}1121^{\circ} \mathrm{C} / 103 \mathrm{MPa} \\
\left(2050^{\circ} \mathrm{F} / 15 \mathrm{ksi}\right)\end{array}$ & & & \\
\hline Rupture Life & 369 & 502 & 599 \\
\hline
\end{tabular}

\section{Heat Treatment and Microstructure}

Single crystal test material has been successfully cast at nine SX foundries with differing thermal gradients and solidification rates using established CMSX-4 casting parameters and produced high first time yields $(90 \%+)$ and excellent chemistry retention. An optimized multi-step solutioning/ homogenization heat treatment cycle was developed which produced nearly complete solutioning of eutectic $\gamma / \gamma^{\prime}$ and no incipient melting (Figure 4). The primary aging temperature and time was optimized to obtain aligned cubic $\gamma^{\prime}$ with approximately $0.45 \mu \mathrm{m}$ size indicating appropriate $\gamma / \gamma^{\prime}$ mismatch (Figure 5).

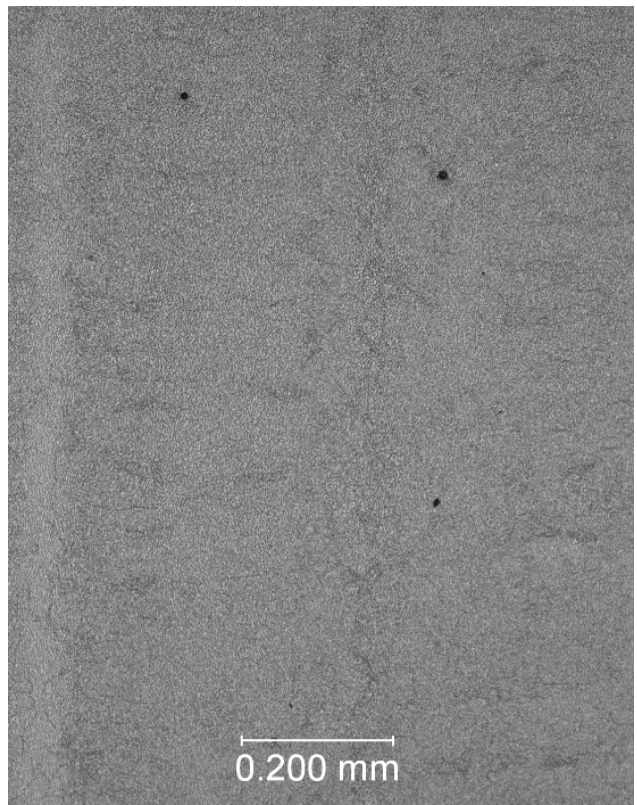

Figure 4. CMSX-4 Plus casting microstructure following solution + double age heat treatment

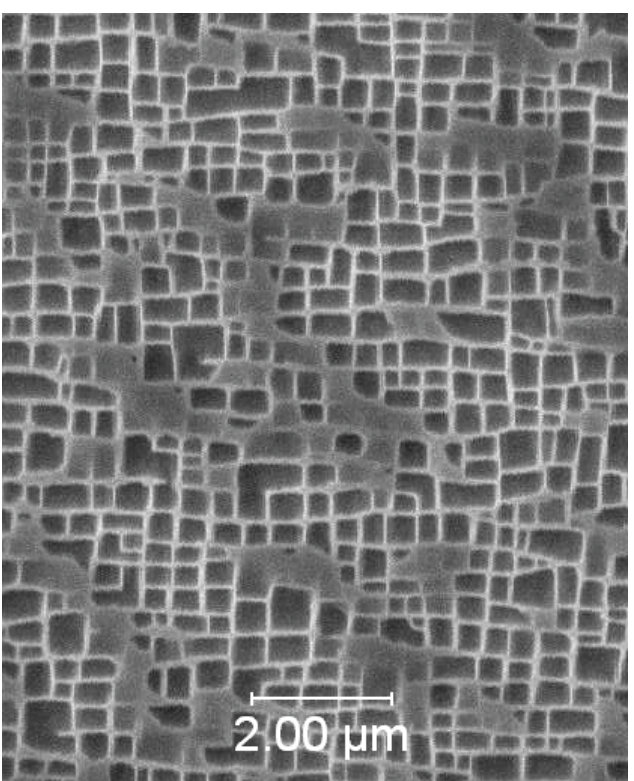

Figure 5. CMSX-4 Plus casting microstructure following solution + double age heat treatment

\section{Mechanical Properties}

Extensive creep/stress rupture, tensile and strain-controlled low cycle fatigue (LCF) property testing have been conducted on CMSX-4 Plus alloy.

\section{Creep/Stress-Rupture}

Consistent with development goals, CMSX-4 Plus alloy has significantly improved creep/stress rupture properties over CMSX4 alloy over a range of temperature/stress conditions (Table IV). The metal temperature improvement in rupture life of CMSX-4 Plus alloy over CMSX-4 alloy is $22^{\circ} \mathrm{C}\left(40^{\circ} \mathrm{F}\right)$ at $982^{\circ} \mathrm{C}\left(1800^{\circ} \mathrm{F}\right)$ and $28^{\circ} \mathrm{C}\left(50{ }^{\circ} \mathrm{F}\right)$ for $1.0 \%$ creep (density corrected). At the very high temperature $1121^{\circ} \mathrm{C} / 103 \mathrm{MPa}\left(2050{ }^{\circ} \mathrm{F} / 15 \mathrm{ksi}\right)$ test condition, CMSX-4 alloy has exceptional stress-rupture life; however, CMSX-4 Plus has nearly equivalent life with improved rupture ductility. Remarkably, the creep-rupture properties of CMSX-4 Plus at $982{ }^{\circ} \mathrm{C} / 248 \mathrm{MPa}\left(1800^{\circ} \mathrm{F} / 36 \mathrm{ksi}\right)$ are similar to $6.3 \mathrm{wt} \%$ Re-containing CMSX-10K alloy and superior at $1121^{\circ} \mathrm{C} / 103 \mathrm{MPa}$ $\left(2050^{\circ} \mathrm{F} / 15 \mathrm{ksi}\right)($ not density corrected) (Table V) [1].

Table IV. CMSX-4 Plus Rupture Life Comparison (hours)

\begin{tabular}{|l|c|c|c|}
\hline Test Condition & CMSX-4 Plus & CMSX-4 & CMSX-8 \\
\hline $\begin{array}{l}913^{\circ} \mathrm{C} / 571 \mathrm{MPa} \\
\left(1675^{\circ} \mathrm{F} / 75 \mathrm{ksi}\right)\end{array}$ & 215 & 52 & 67 \\
\hline $\begin{array}{l}982^{\circ} \mathrm{C} / 248 \mathrm{MPa} \\
\left(1800^{\circ} \mathrm{F} / 36 \mathrm{ksi}\right)\end{array}$ & 732 & 280 & 236 \\
\hline $\begin{array}{l}982^{\circ} \mathrm{C} / 296 \mathrm{MPa} \\
\left(1800^{\circ} \mathrm{F} / 43 \mathrm{ksi}\right)\end{array}$ & 276 & 88 & 89 \\
\hline $\begin{array}{l}1010^{\circ} \mathrm{C} / 248 \mathrm{MPa} \\
\left(1850^{\circ} \mathrm{F} / 36 \mathrm{ksi}\right)\end{array}$ & 227 & 82 & 85 \\
\hline $\begin{array}{l}1050^{\circ} \mathrm{C} / 190 \mathrm{MPa} \\
\left(1922^{\circ} \mathrm{F} / 27.6 \mathrm{ksi}\right)\end{array}$ & 231 & 90 & 81 \\
\hline $\begin{array}{l}1121^{\circ} \mathrm{C} / 103 \mathrm{MPa} \\
\left(2050^{\circ} \mathrm{F} / 15 \mathrm{ksi}\right)\end{array}$ & 599 & 640 & 293 \\
\hline
\end{tabular}


Table V. CMSX-4 Plus/CMSX-10K

Creep-Rupture Comparison (hours)

\begin{tabular}{|c|l|c|c|c|}
\hline \multirow{2}{*}{ Test Condition } & Alloy & $\begin{array}{c}\text { Rupture } \\
\text { Life }\end{array}$ & $\begin{array}{l}\text { Time } \\
\text { to } 1 \%\end{array}$ & $\begin{array}{c}\text { Time } \\
\text { to } 2 \%\end{array}$ \\
\hline $982^{\circ} \mathrm{C} / 248 \mathrm{MPa}$ & CMSX-4 Plus & $732 \mathrm{hrs}$ & 433 & 486 \\
\cline { 2 - 5 }$\left(1800^{\circ} \mathrm{F} / 36 \mathrm{ksi}\right)$ & CMSX-10K & 718 & 390 & 459 \\
\hline $1121^{\circ} \mathrm{C} / 103 \mathrm{MPa}$ & CMSX-4 Plus & 599 & -- & -- \\
\cline { 2 - 6 }$\left(2050^{\circ} \mathrm{F} / 15 \mathrm{ksi}\right)$ & CMSX-10K & 558 & -- & -- \\
\hline \multicolumn{4}{|c}{ (not density corrected) }
\end{tabular}

Larson-Miller diagrams of CMSX-4 Plus alloy rupture life and time to $1 \%$ creep in comparison to $2^{\text {nd }}$ generation alloys CMSX-4 and
René N5 are shown in Figures 6-7 and demonstrate the improvement in these properties [3, 11, 12].

Post stress-rupture metallography following 606 hours at $1121{ }^{\circ} \mathrm{C}$ $\left(2050^{\circ} \mathrm{F}\right)$ shows a typical rafted microstructure and excellent phase stability with negligible TCP phase formation (Figure 8). It was noted that the amount of TCP phase visually observed in CMSX-4 Plus alloy is less than observed for CMSX-4 alloy following similar test exposure. In addition, the TCP phase is not associated with creep cracking nor is there evidence of significant de-alloying. This stability is further indicated by no fall-off in the linear $\log _{10}$ stress vs. $\log _{10}$ time stress-rupture curves shown in Figure 9.

\section{Larson-Miller Rupture Life}

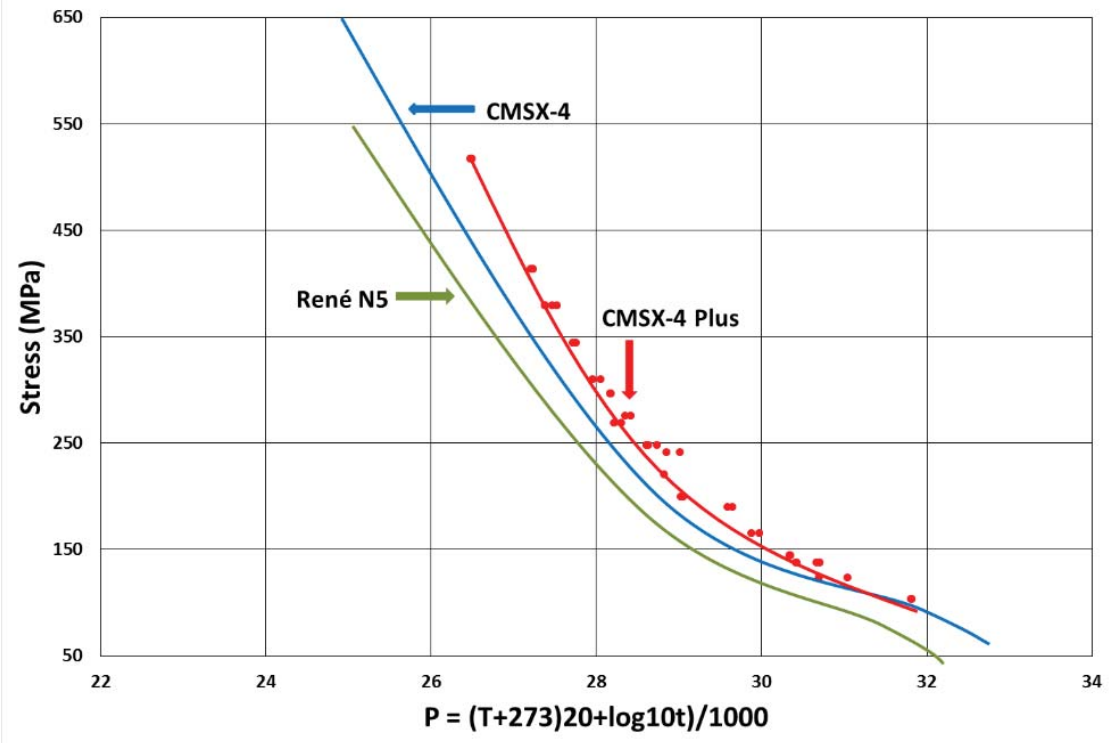

Figure 6. Larson-Miller Rupture life of CMSX-4 Plus vs.

CMSX-4 and René N5 alloys

\section{Larson-Miller Time to $1 \%$ Creep}

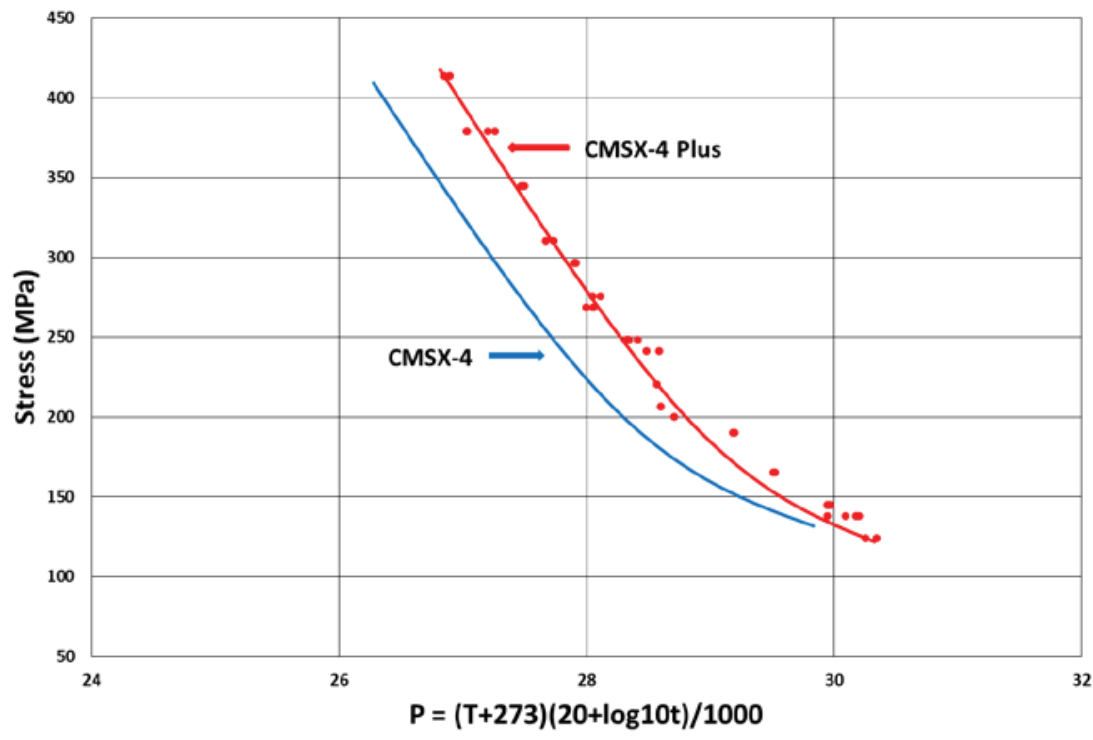

Figure 7. Larson-Miller Time to $1 \%$ creep

CMSX-4 Plus alloy vs. CMSX-4 


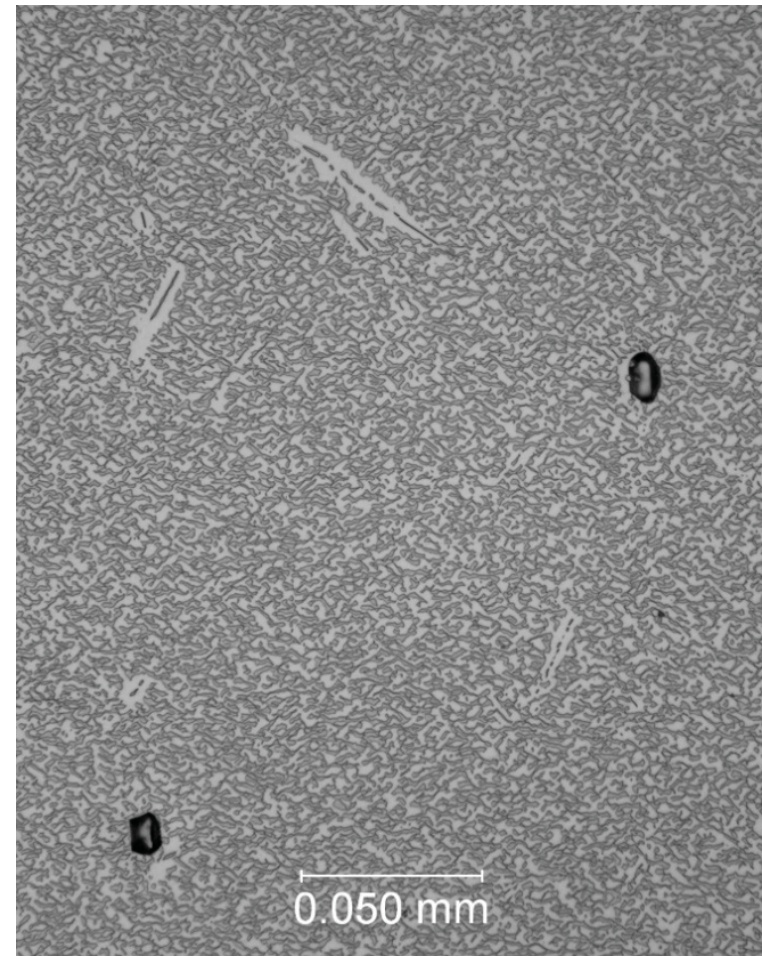

(a)

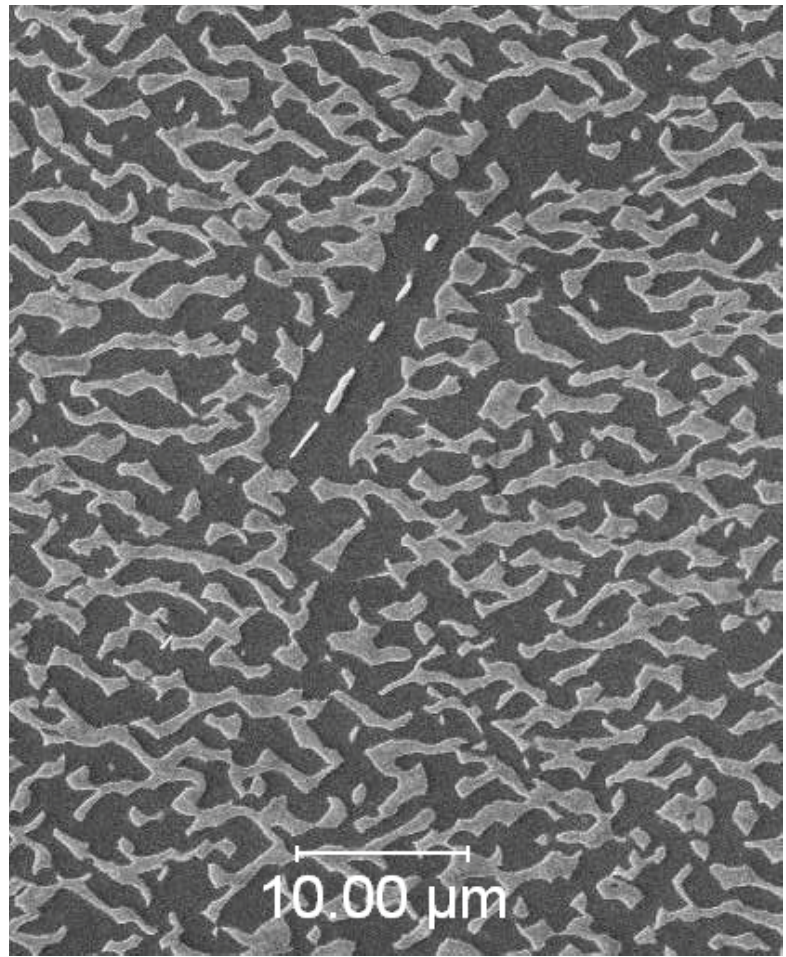

(b)

Figure 8. Post-test microstructure after stress-rupture testing at $1121^{\circ} \mathrm{C} / 103 \mathrm{MPa}$ for 606 hours

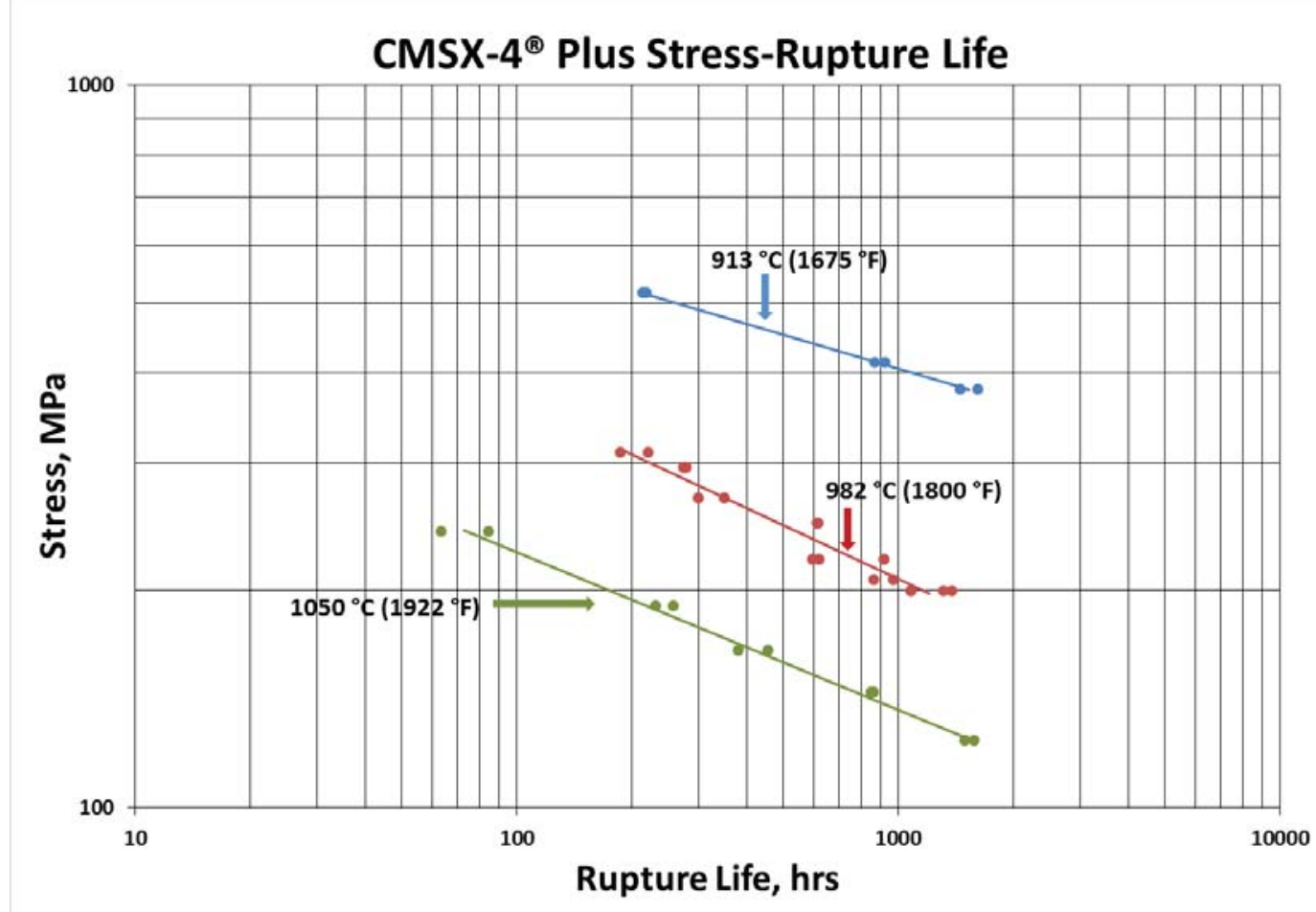

Figure 9. CMSX-4 Plus Alloy Stress-Rupture Curves 
In addition to standard $4.52 \mathrm{~mm}(0.178 \mathrm{inch})$ diameter test bar creep and stress rupture data, stress-rupture testing was also run on minibar and mini-flat specimens machined from a solid single crystal turbine blade casting, as shown in Figure 10. Mini-bar data (1.52 $\mathrm{mm} / 0.060$ " diameter) is indicative of the retention of thick section properties for thinner wall designs. Excellent retention of properties was found on these subsize specimens. Similarly, mini-flat specimens $\left(0.51 \mathrm{~mm} / 0.020^{\prime \prime}\right.$ thick $)$ give an indication of the influence of bare oxidation degradation to thin wall properties. Stress-rupture lives show excellent thin-wall property retention and suggest good high temperature bare oxidation resistance for this alloy.

\section{Non-isothermal Creep}

Evaluation of very high temperature non-isothermal creep performance has been conducted in conjunction with ENSMA. The ENSMA work shows CMSX-4 Plus alloy has significantly superior performance, approaching CMSX-10K alloy, in relation to singleengine-out helicopter requirements compared to CMSX-4 and other commercial SX alloys (Figure 11) [13,14].

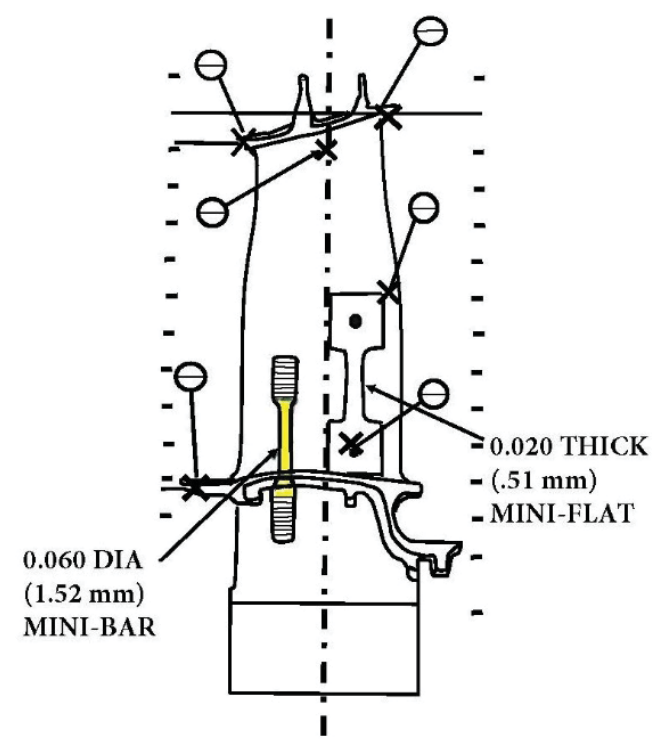

Figure 10. Schematic drawing of machined from blade specimens

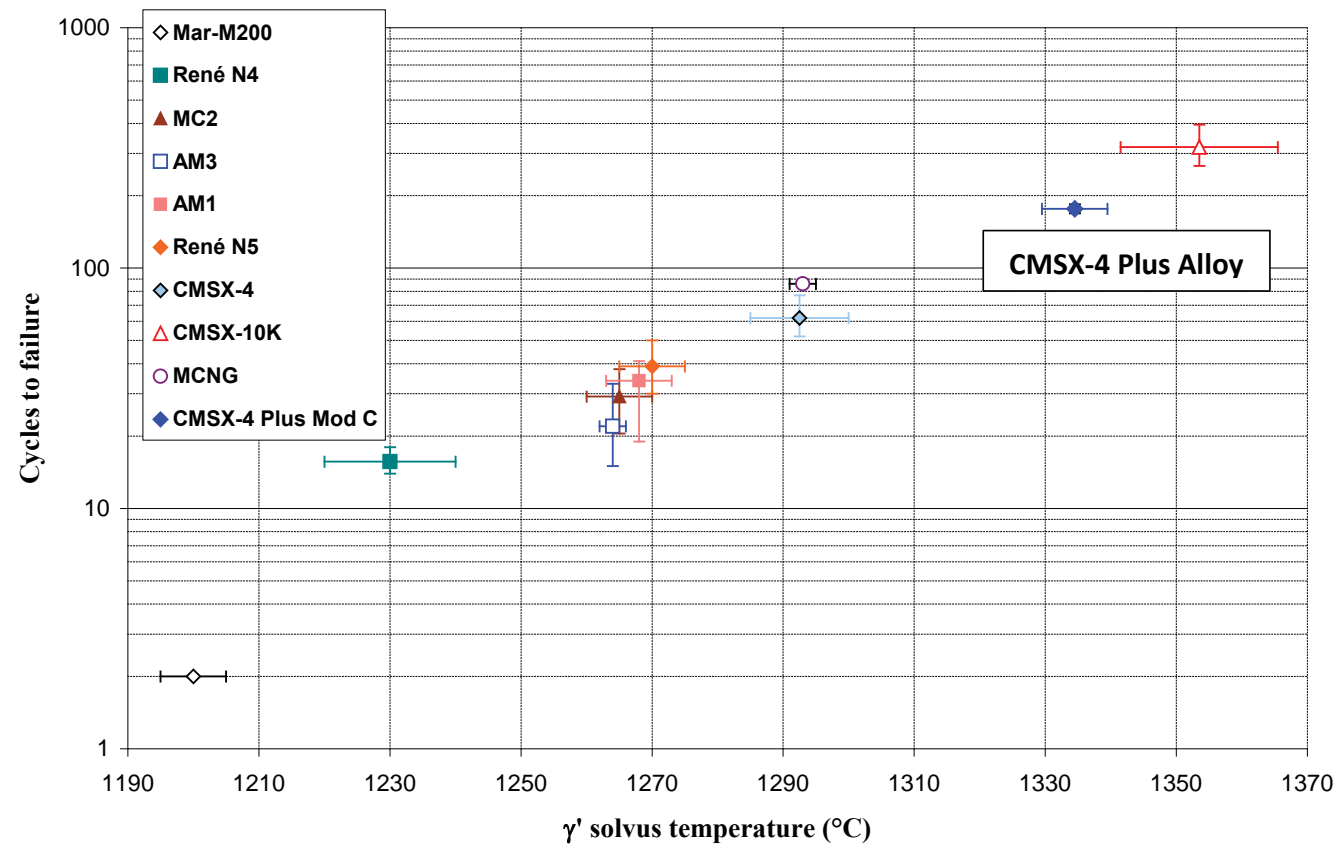

Figure 11. Correlation of thermal cycling creep strength vs. $\gamma^{\prime}$ solvus temperature

$\underline{\text { Tensile }}$

CMSX-4 Plus tensile properties as a function of temperature are shown in Figures 12 and 13 and exhibit excellent strength peaking at $760^{\circ} \mathrm{C}\left(1400^{\circ} \mathrm{F}\right)$ while maintaining very good ductility.

\section{Low Cycle Fatigue}

Limited strain-controlled LCF testing of CMSX-4 Plus alloy has been conducted at $1038{ }^{\circ} \mathrm{C}\left(1900{ }^{\circ} \mathrm{F}\right)$ to compare with baseline CMSX-4 alloy. Given the small number of specimens available for testing and the expected higher temperature capability of CMSX-4 Plus, $1038^{\circ} \mathrm{C}$ was selected as a better temperature to test LCF than at lower temperatures for the purpose of differentiating the two materials.
Typical S-N curves $(\mathrm{R}=0$ and $\mathrm{R}=-1)$ for cycles to initiation are shown in Figure 14. It should be noted that the CMSX-4 Plus specimens were in the solutioned and double aged condition, whereas the CMSX-4 baseline represents HIP + solution and aged material. This limited data indicates CMSX-4 Plus is better in LCF than CMSX-4, particularly at shorter lives or higher stresses; at longer lives, the two materials appear to be comparable. At $1038^{\circ} \mathrm{C}$, there is some creep/fatigue interaction, and the better LCF performance of CMSX-4 Plus at higher stresses may the result of its improved creep behavior. This suggests that the ultimate advantage of CMSX-4 Plus lies in its superior creep performance and how creep impacts LCF at temperatures where creep/fatigue interaction occurs [15]. 
Strain-Controlled LCF $1038^{\circ} \mathrm{C}\left(1900^{\circ} \mathrm{F}\right), \mathrm{R}=0$

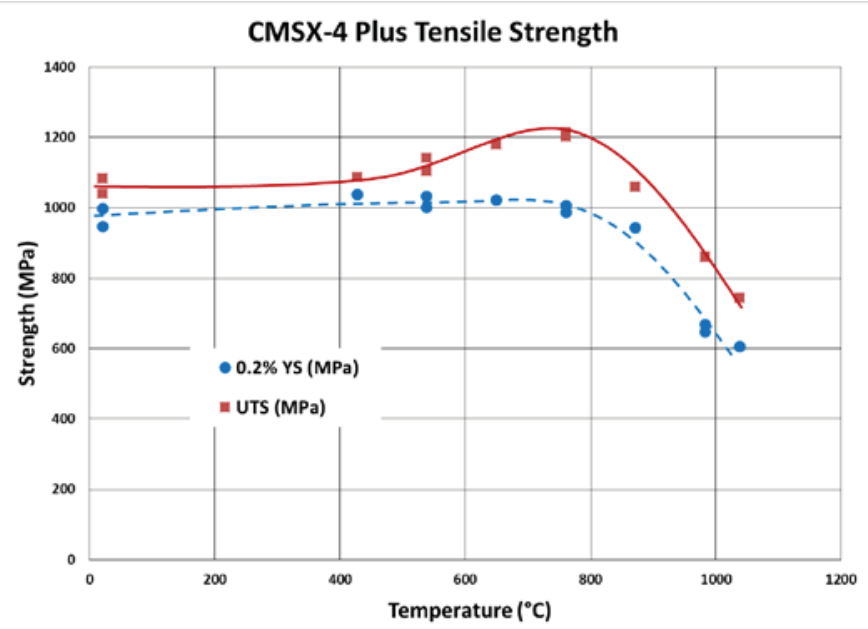

Figure 12. CMSX-4 Plus Tensile Strength vs. Temperature

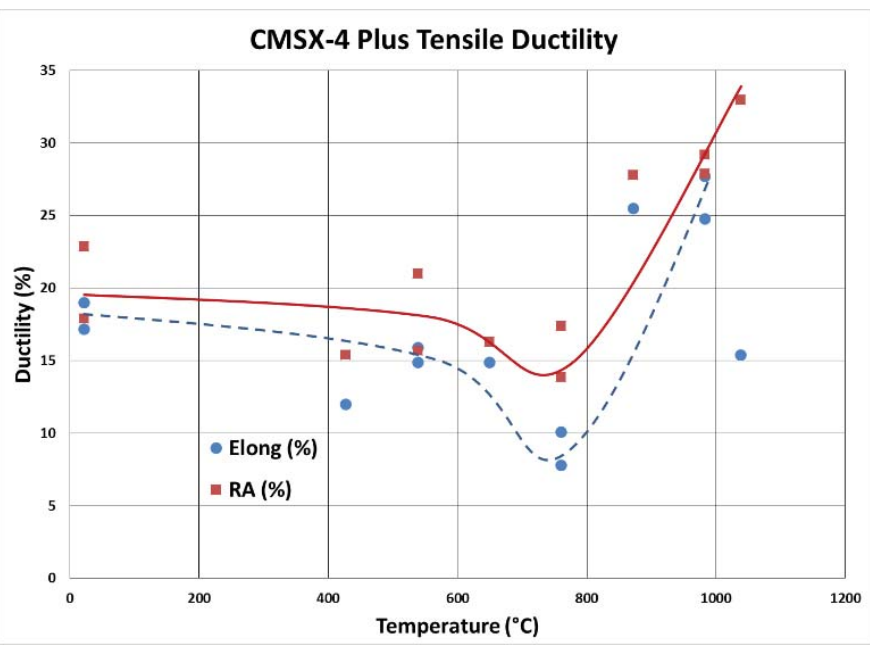

Figure 13. CMSX-4 Plus Tensile Ductility vs. Temperature

\section{Physical Properties}

Physical properties of CMSX-4 Plus alloy have been extensively characterized in collaboration with the National Physical Laboratory (NPL) in the UK. CMSX-4 Plus alloy density at room temperature is $8.927 \mathrm{~g} / \mathrm{cm}^{3}$ which is intermediate for commercial SX alloys and lower than alloys PWA 1484 and CMSX-10K/10N (Table VI). Density, Young's and shear moduli, diffusivity, thermal conductivity, and expansion coefficient as a function of temperature are shown in Figures 15-19.
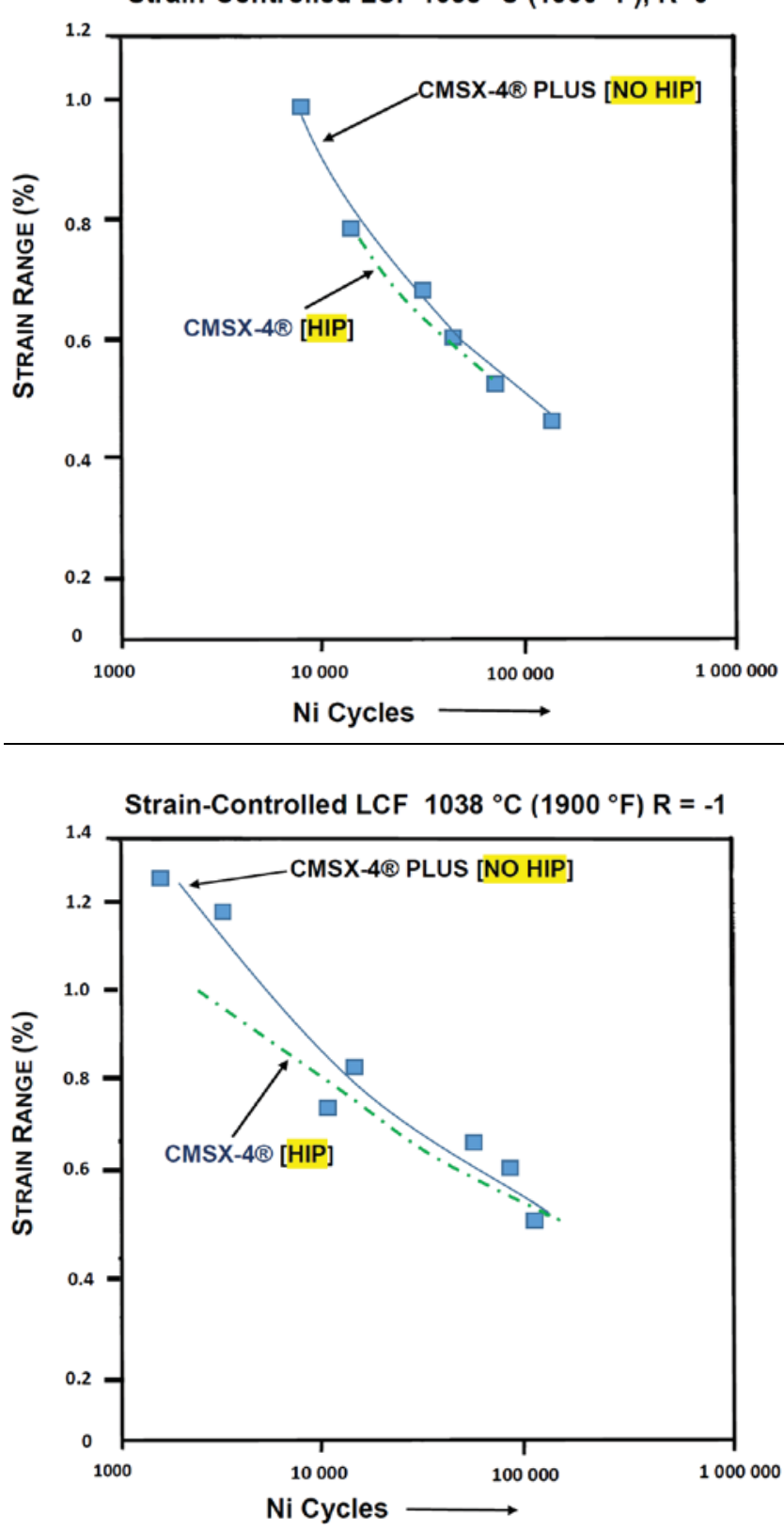

Figure 14. CMSX-4 Plus vs. CMSX-4 $1038^{\circ} \mathrm{C}\left(1900{ }^{\circ} \mathrm{F}\right) \mathrm{LCF}$

Table VI. Room Temperature Density of Commercial Alloys

\begin{tabular}{|l|c|}
\hline Alloy & $\begin{array}{c}\text { Room Temperature } \\
\text { Density }\left(\mathrm{g} / \mathrm{cm}^{3}\right)\end{array}$ \\
\hline AM1 & 8.59 \\
\hline CMSX-4 & 8.70 \\
\hline SC180 & 8.84 \\
\hline CMSX-4 Plus & 8.93 \\
\hline PWA 1484 & 8.95 \\
\hline René N6 & 8.97 \\
\hline CMSX-10K & 9.05 \\
\hline
\end{tabular}




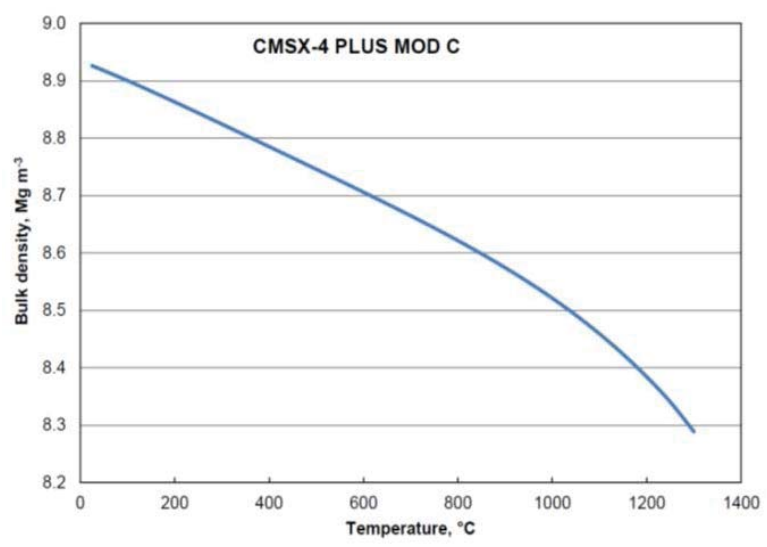

Figure 15. CMSX-4 Plus Density as a function of Temperature

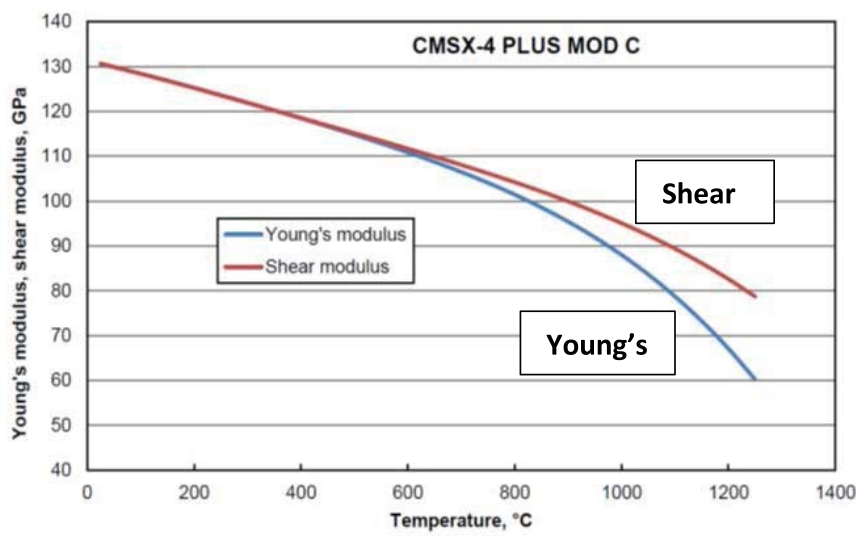

Figure 16. Young's \& Shear Modulus vs. Temperature for CMSX-4 Plus alloy

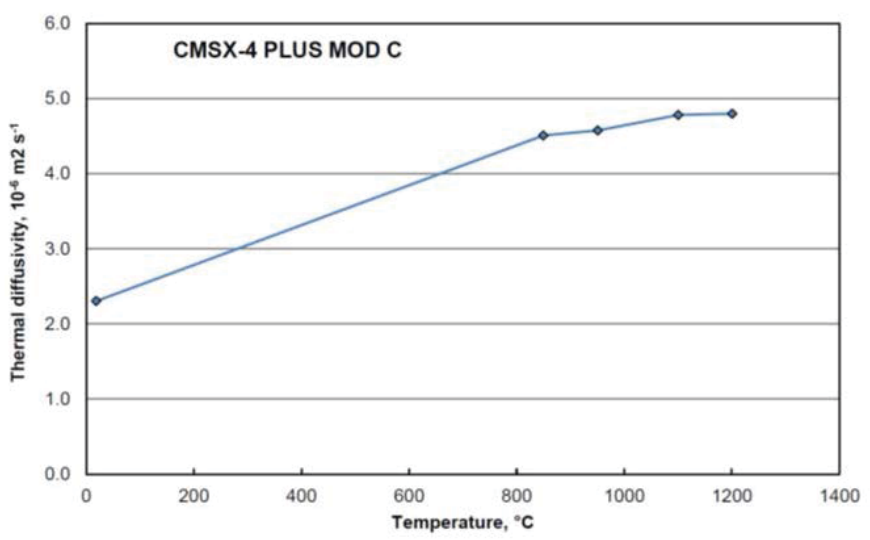

Figure 17. CMSX-4 Plus Thermal Diffusivity vs. Temperature

Producibility and Applications Development

CMSX-4 Plus alloy has been successfully scaled to production heat status on the Cannon-Muskegon 2.3 ton $/ 5,000 \mathrm{lb}$. V-6 VIM furnace. This alloy has been cast by ten experienced SX foundries in the United States and Europe. In all cases, the casters have demonstrated good first time yield, chemistry retention and as-cast microporosity levels. As such, HIP may not be required for all turbine blade applications. Post-cast processing and heat treatment

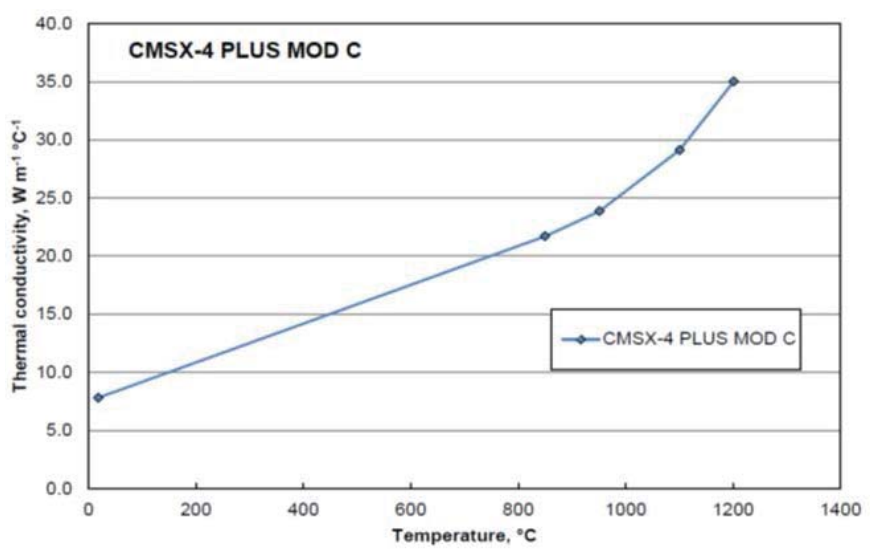

Figure 18. CMSX-4 Plus Thermal Conductivity vs. Temperature

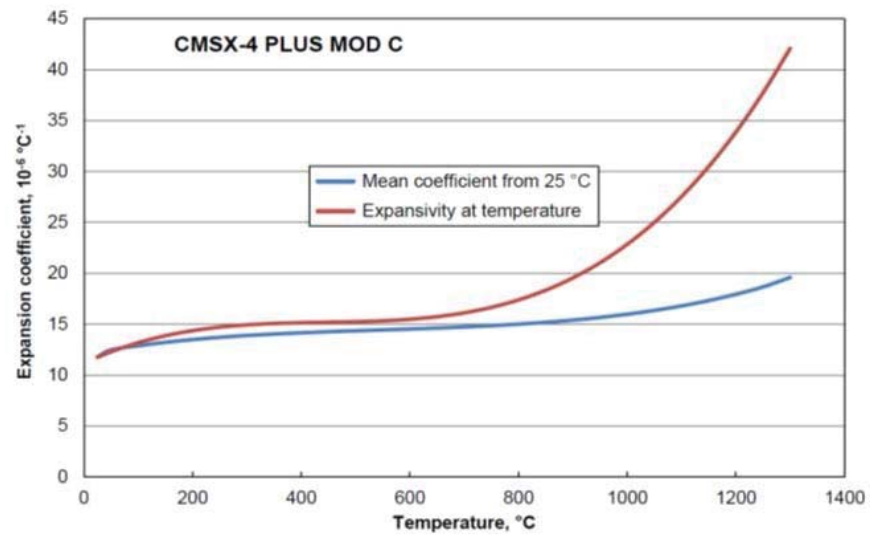

Figure 19. Expansion Coefficient vs. Temperature for CMSX-4 Plus alloy

has demonstrated a low propensity for recrystallization and can be extensively solutioned to $99 \%$ + without incipient melting issues.

As previously discussed, high Re content SX alloys tend to develop SRZ phase instability in the base alloy adjacent to the coatings. An example of this from an engine run CMSX-10N blade is shown in Figure 20. Formation of the SRZ phases can produce crack initiation following high temperature stressed exposure and can result in reduction of long term creep-rupture properties. However, examination of SX cast CMSX-4 Plus alloy following 250 hours of very high temperature exposure under a TBC bond coat has shown zero occurrence of SRZ (TCP) phase [16].

Alloy evaluation and design database generation is underway at multiple OEMs with flight engine test programs commencing in 2016. 


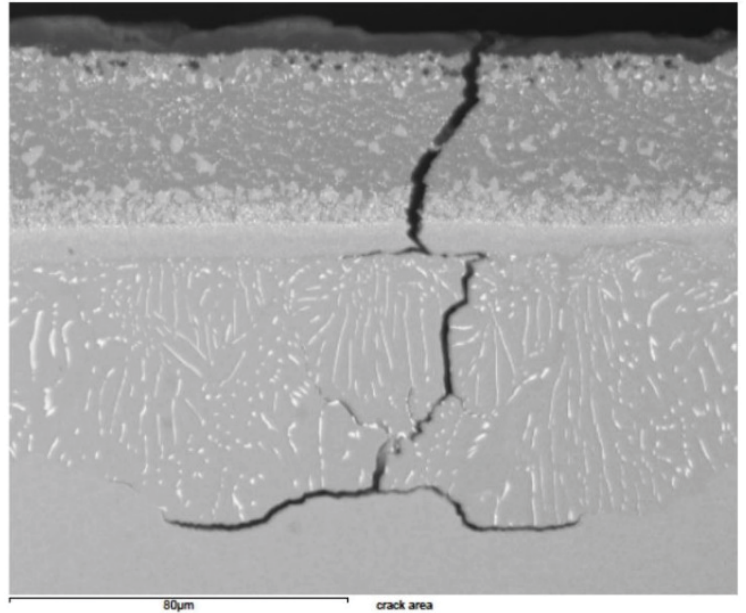

Figure 20. CMSX-10N engine run blade showing SRZ phase and associated cracking near the blade tip

\section{Summary}

A new, improved $3^{\text {rd }}$ generation SX superalloy, CMSX-4 Plus has been successfully developed and characterized. This $4.8 \% \mathrm{Re}-$ containing alloy demonstrates it is suitable to replace both $2^{\text {nd }}$ generation CMSX-4 alloy and $3^{\text {rd }}$ generation CMSX-10K/N alloys with improved properties and performance and lacking the drawbacks of current $3^{\text {rd }}$ generation SX alloys.

\section{Acknowledgements}

Special thanks to the following individuals for their collaboration

\section{David Ford}

Judith Funk, Paul Wheelock, Eugene Sun - Rolls-Royce Corp.

Bob Plecki - Joliet Metallurgical Laboratories

Roger Morrell - NPL

Jonathan Cormier - ENSMA

Tom Versalle - Cannon-Muskegon

\section{References}

1. U.S. Patent No. 5,366,695, "Single Crystal Nickel-based Superalloy", published 22 November 1994.

2. U.S. Patent No. 5,540,790, "Single Crystal Nickel-based Superalloy”, published 30 July 1996.

3. W.S. Walston et al., "Rene' N6: Third Generation Single Crystal Superalloy," Superalloys 1996 (Warrendale, PA: TMS, 1996), $27-$ 34.

4. W.S. Walston et al., "A New type of Microstructural Instability in Superalloys - SRZ," Superalloys 1996 (Warrendale, PA: TMS, 1996), 9-18.

5. Japanese Patent No. 5876915, "High Strength Single Crystal Superalloy", granted 29 January 2016.

6. Jacqueline B. Wahl and Ken Harris, "New Single Crystal Superalloys, CMSX-7® and CMSX-8®," Superalloys 2012 (Warrendale, PA: TMS 2012), 179-188.
7. Jacqueline B. Wahl and Ken Harris, "New Single Crystal Superalloys CMSX-8 and CMSX-7," Proceedings of Turbo Expo 2014, GT2014-25155. 16-20 June 2014 Dusseldorf, Germany.

8. Ken Harris and Jacqueline B. Wahl, "High Stength Single Crystal Nickel Base Superalloy" in the European Patent Office, 2015, EP 2,942,411 A1: Europe.

9. U.S. Patent Application No, 14/272627, "High Strength Single Crystal Alloy", filing date 8 May, 2014, Patent Pending.

10. Anthony Geimei Dedicatee Presentation, "The Development of Single Crystal Superalloys," SUPERALLOYS 2012 Conference, 913 September 2012, Seven Springs, PA.

11. D.J. Frasier et al., "Process and Alloy Optimization for CMSX$4{ }^{\circledR}$ Superalloy Single Crystal Airfoils," (Paper Presented at Cost 501/505 High Temperature Materials for Power Engineering 1990 Conference, Liege, Belgium, 24-27 September, 1990).

12. Paul J. Fink, Joshua L. Miller and Douglas G. Konitzer, "Rhenium Reduction - Alloy Design Using an Economically Strategic Element," JOM, Vol. 62 No. 1 (Jan. 2010), 55-57.

13. Jonathan Cormier, "Thermal Cycling Creep Resistance of Nibased Single Crystal Alloys," Superalloys 2016 (Warrendale, PA: TMS, 2016).

14. Aerospace Daily \& Defense Report, "Turbomeca Considering Flight Testing 'Sleeping Engine' Tech," Aviation Week Network, 8 Feb. 2016, pg 3

15. Eugene Sun, private communication with authors, Rolls-Royce Corporation, 4 May 2015.

16. Virginie Jaquet, private communication with authors, Safran/SNECMA, 15 June 2015. 